\title{
The study for analysis of acidity and moisture in paper record by mobile small NIR spectrometer
}

\author{
Chang Yong Lee, Chan Bong Kim ${ }^{1, \star}$, Seong Uk Lee ${ }^{1}$, Won Bo Cho ${ }^{1}$ and Hyo Jin Kim ${ }^{1}$ \\ National Archives of Korea, Archives Management Division, Daewangpangyoro 398, \\ Sujeong-gu, Seongnam-si, Gyeonggi-do 461-370, Korea \\ ${ }^{1}$ Bruker Optics Korea. Co., Ltd 23-1 14F KINS Tower, Jeongja-dong, Seongnam-Si, \\ Gyeonggi-do 463-847, Korea \\ (Received September 18, 2012; Revised October 12, 2012; Accepted October 12, 2012)
}

\section{이동 가능한 소형 근적외선 분광 분석기를 사용한 종이 기록물 내 산성도 및 함수율 분석에 대한 연구 \\ 이창영 $\cdot$ 김찬봉 ${ }^{1} \star$. 이성욱 ${ }^{1} \cdot$ 조원보 ${ }^{1} \cdot$ 김효진 $^{1}$ \\ 국가 기록원 기록관리부, ${ }^{1}$ 브러커옵틱스 코리아(주) \\ (2012. 9. 18. 접수, 2012. 10. 12. 수정, 2012. 10. 12. 승인)}

\begin{abstract}
As for quality evaluation of paper records, it is very important to measure acidity and moisture in paper. In the case important paper records, it should be measured directly in field. But ISO standard analytical method would be limited to measure directly in field for quality evaluation of paper records until now. Therefore it could be to use mobile small NIR spectrometer for being analyzed by direct and non-invasive method in field. The wavelength range of small spectrometer has from 900 to $1700 \mathrm{~nm}$, and the surface of paper could be measured by diffused reflected optical fiber probe. Thus, the acidity and moisture could be analyzed on the paper record with from 1970 to 2003. As the result, it could be confirmed to have each more than 0.9 as the correlation of acidity and moisture. Thus, it will be possible to develope the evaluation system of paper record with mobile small NIR spectrometer and optical fiber by the result.

요 약: 종이 기록물의 품질 평가에 있어서, 종이 내에 산성도와 함수율이 중요하다. 특히 중요한 종이 기록물에 있어서는 현장에 가서 직접 측정해야 하는데, 현재의 종이 기록물의 품질 평가하는 ISO 표준 분석 방법의 경우에는 파괴적인 방법이면서 현장에서 직접 분석하기에는 한계가 있다. 따라서 본 연구에 서는 현장에서 직접 측정하면서 비파괴적인 방법으로 분석하기 위해서, 이동 가능한 소형 비파괴 분석기 인 근적외선 분광 분석기를 사용하였다. 소형 분광기의 파장 대역은 900 부터 $1700 \mathrm{~nm}$ 파장 대역을 사용 하였으며, 확산 반사형 광화이버를 사용하여 종이의 표면에 측정하였다. 그리고 1970 년대부터 2003년까 지의 종이 기록물을 사용하여 산성도와 함수율을 측정하였다. 측정 결과는 산성도와 함수율이 각각 0.9 이상으로 두 인자에 대한 높은 상관관계를 확인 하였다. 이로써 소형 근적외선 분광 분석기와 광화이버 를 사용하여 이동하면서 종이 기록물의 평가 시스템 개발이 가능한 것으로 확인 되었다.
\end{abstract}

Key words: Mobile small spectrometer, Paper record, NIR

Corresponding author

Phone : +82-(0)2-940-4305 Fax : +82-(0)2-943-9578

E-mail : chowonbo@naver.com 


\section{1. 서 론}

종이 기록물은 일반적으로 기록 방법 중에서 하나 로써 기록물은 주로 여러 매체로 기록된 정보 자료로 써 오랫동안 저장 보관 되어 진다. 이중에서 상당 부 분을 종이에 의해서 기록되고 있다. 종이 기록물의 전 체 기록물 중에서 $95 \%$ 이상을 점유 하고 있다. 이들 종이 기록물은 문서, 도면으로 분류되어 관리되고 있 다. 이러한 종이 기록물을 안전하고 항구적으로 보존 하기 위하여 물리, 화학적인 분석에 있어서는 종이 중 일부 샘플링을 통하여 분석을 실시하고 있다. ${ }^{1}$ 이러한 샘플링 방법은 기록물에 희귀 기록물 일수록 기록물 보존을 위하여 샘플링 분석이 있어 한계가 있어 항구 적 보존에 있어 장애가 되고 있다. 그리고 푸리에 변 환 근적외선 분광기를 사용하여 근적외선과 종이 기 록물의 $\mathrm{pH}$ 에 대한 상관 관계에 대한 연구를 하였다. 본 연구에서는 장소 구애 없이 이동이 가능한 소형 근적외선 분광기를 사용하여 장소 구분 없이 측정 할 수 있는 이동 가능한 분광기를 사용하여 연구 하였다. 이 소형 분광기는 가시광선(Visible range)과 중적외선 (Mid infrared range)영역으로써, 전체 근적외선 영역 은 700 부터 $2500 \mathrm{~nm}$ 영역이며, 본 연구에서 사용된 파장 대역은 그 중에서 주로 배음대(Overtone) 영역인 $900 \mathrm{~nm}$ 부터 $1700 \mathrm{~nm}$ 를 사용하였는데, 이 파장 대역 은 주로 C-H, N-H, O-H 작용기의 배음 대역으로써 정 량 분석에 널리 사용되고 있다. ${ }^{2}$ 그리고 배음대역 분광기에 오목 회절발을 사용하여 동시에 광을 회절 시키는 방식을 채택하였으며, 광 손실 없이 광 전송이 가능한 광파이버 사용하여 1970 년대 이후의 종이 기 록물을 측정하였다., 3 그리고 정량 분석을 위하여 계 량분석화학(chemometrics)기법 중 부분최소자승법(PLS method, partial least squares method)을 이용하였다. ${ }^{5}$

\section{2. 실 험}

\section{1. 공시 재료 및 ISO 표준 방법}

본 실험에서 사용한 공시 재료는 국가 기록원이 보 유하고 있는 종이 기록물 중에서 1970 년대부터 2003 년까지의 종이 기록물 66 점을 사용하여 측정하였다. 공시 재료는 온도 $23 \pm 3{ }^{\circ} \mathrm{C}$, 상대습도 $50 \pm 5 \%$ 의 조건 에서 48 시간 안정화한 후 측정하도록 하였다. 함수율 을 측정하기 위해서는 종이에 포함된 수분의 함유량 을 측정하게 되는데, ISO 표준 방법인 ISO 11093-3 근거로 하여 수분의 함수율을 측정하였다. ${ }^{6}$ 그리고 산

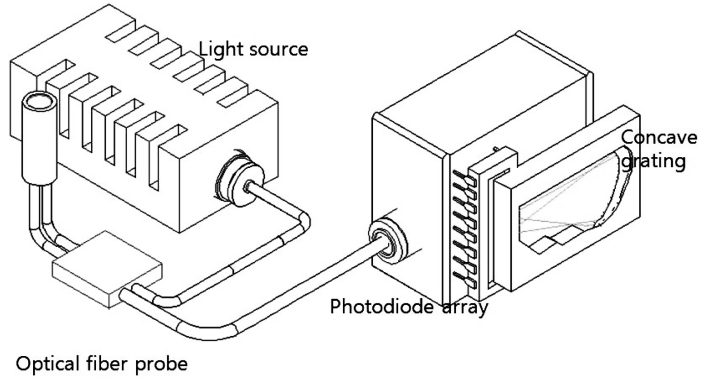

Fig. 1. Schematic diagram of mobile small NIR spectrometer with optic fiber probe.

성도의 경우에는 종이 섬유의 산성도로써 $\mathrm{pH}$ 를 사용 하여 산성도를 확인 하였다. ${ }^{7}$

\section{2. 측정 방법}

본 연구에서 사용한 소형 근적외선 분광 분석기는 Fig. 1에 보는 것과 같이 전체 근적외선 영역 중에서 $900 \mathrm{~nm}$ 부터 $1700 \mathrm{~nm}$ 파장 대역을 측정하는 분광기 (Spectrometer)를 사용하였다. 이 분광기의 구성요소를 보면, 고정형 오목 회절발(Fixed concave grating)과 이 고정형 오목 회절발에서 회절된 광을 동시에 측정하 기 위하여 검출기 부분을 다이오드 어레이 검출기 (Diode array detector)를 사용하여 측정한다. 이 스펙 트로미터는 장점은 고정형 오목 회절 발이기 때문에 이동이 가능할 뿐만 아니라 측정 시간이 수 수십 $\mathrm{msec}$ 이기 때문에 짧은 시간 내에 원하는 장소에서 종 이 기록물을 분석 할 수 있다. 그리고 종이를 측정하 기 위하여 스펙트로미터에 광파이버를 연결하고, 근적 외선 광원인 텅스텐-할로겐 램프(Tungsten halogen lamp)에 광화이버를 연결한 후 종이에 대해서 확산 반 사(Diffused reflectance)로 측정한다. 광화이버의 직경 이 $400 \mu \mathrm{m}$ 로써 종이에 좁은 영역을 측정할 수 있어 종이가 시간에 지남에 따라서 종이의 일부분에 대한 상태 평가가 가능하다.

\section{3. 결과 및 고찰}

\section{1. 소형 근적외선 흡수 스펙트럼 특성 연구}

Fig. 2는 전처리를 하지 않은 비파괴 광파이버용 근 적외선 분석 장치를 사용하여 측정한 스펙트럼으로써 각 종이의 두께에 따라서 바탕 스펙트럼의 변화를 볼 수 있다. 바탕 스펙트럼인 0 에서부터 $0.5 \mathrm{AU}$ 까지 변화 되는 것으로 볼 수 있다. 하지만 $1400 \mathrm{~nm}$ 부터 1600 $\mathrm{nm}$ 까지의 파장 대역에서 흡수 스펙트럼이 나타나는 


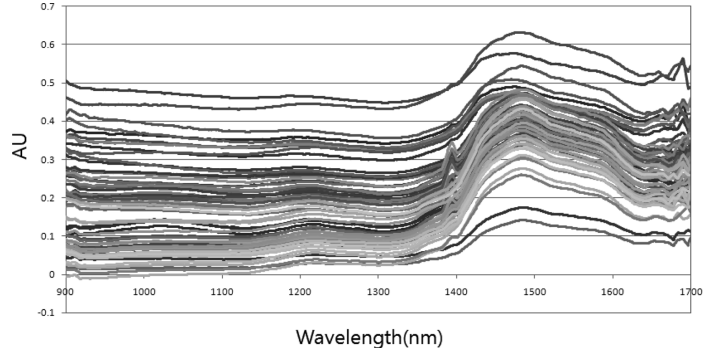

Fig. 2. Full raw spectra of NIR spectrometer.

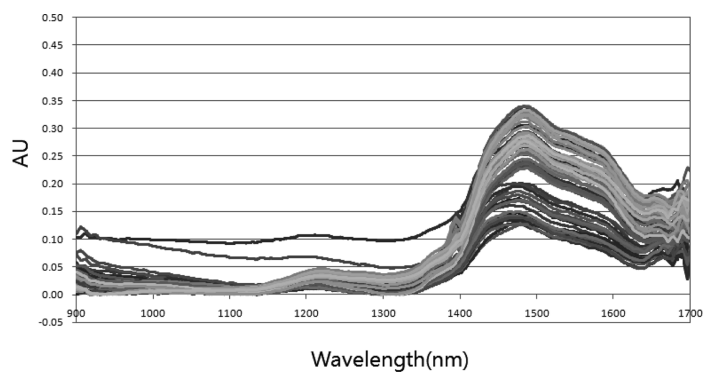

Fig. 3. Full spectra of NIR spectrometer by baseline correction.

것을 볼 수 있었다. 이러한 바탕스펙트럼을 안정화하기 위해서 여러 가지 전처리 방법 중에서 baseline correction 방법을 사용하여 바탕 스펙트럼 보정하였다. 이러한 바탕선 보정 된 결과는 Fig. 3의 흡수 스펙트 럼이다. Baseline correction은 결과 일부 시료를 제외 한 나머지는 0 에 가깝게 바탕 스펙트럼이 안정화 되 는 것을 확인 할 수 있었다. 전처리 한 후 전체 스펙 트럼에서 보면 $1200 \mathrm{~nm}$ 대역과 $1400 \mathrm{~nm}$ 부터 1600 $\mathrm{nm}$ 에서 흡수 스펙트럼을 확인 할 수 있었는데, 1200 $\mathrm{nm}$ 의 경우에는 바탕 스펙트럼이 불안정한 경우에는 흡수 스펙트럼이 나타나는 지 확인이 안되지만 전처 리 한 후 $1200 \mathrm{~nm}$ 대역에서도 흡수 스펙트럼을 확인 할 수 있었다. 그리고 $1400 \mathrm{~nm}$ 부터 $1600 \mathrm{~nm}$ 대역는 주로 $\mathrm{O}-\mathrm{H}$ 와 $\mathrm{R}-\mathrm{OH}$ 의 1차 배음대(overtones band)와 cellulose의 $\mathrm{O}-\mathrm{H} 1$ 차 배음대의 파장 대역 ${ }^{8}$ 으로써 이 부 분에 대한 자세한 스펙트럼 변화를 확인하기 위하여 1 차 미분(First derivative)을 통하여 이 흡수 스펙트럼을 확인 하였다.

Fig. 4는 1차 미분에 의한 비파괴 광파이버용 근적 외선 흡수 스펙트럼이다. 1차 미분을 통하여 근적외선 흡수 스펙트럼을 확인 한 결과 $1400 \mathrm{~nm}$ 부터 1600 $\mathrm{nm}$ 파장대역의 흡수 스펙트럼이 여러 개의 흡수 스펙 트럼으로 분해되는 것으로 확인 할 수 있었다. 특히 이 중에서 $1400 \mathrm{~nm}$ 부터 $1450 \mathrm{~nm}$ 까지 높은 흡광도가

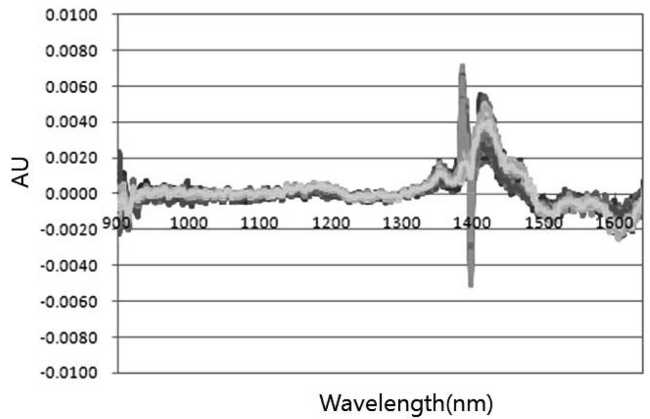

Fig. 4. Full spectra of NIR spectrometer by 1st derivative.

확인 되는데 이 파장 대역은 O-H 1차 배음대역이다. 그리고 $1500 \mathrm{~nm}$ 와 $1600 \mathrm{~nm}$ 파장 대역은 cellulose의 $\mathrm{O}-\mathrm{H}$ 1차 배음대으로써 확인 되었다. 그리고 $1200 \mathrm{~nm}$ 파장 대역은 넓은 파장 대역임에도 불구하고 더 이상 스펙트럼 분해되지 아니하기 때문에 C-H 2 차 배음대 ${ }^{9}$ 로 확인 할 수 있었다.

\section{2. 종이의 산성도에 대한 정량 분석}

종이 기록물의 상태 평가 중에서 산성도를 평가하 기 위하여 $\mathrm{pH}$ 측정은 $\mathrm{pH} \mathrm{4,9}$ 에서 보정 한 후 종이 시료 위에 소량의 증류수에 담근 후, 산성 물질이 용 해되도록 3 분간 유지 한 후, $\mathrm{pH}$ 측정기(Orion 3-star, $\mathrm{USA}$ )로 측정하였다. 이때 측정된 산성도가 5.13부터 9.61까지 영역을 가진 60점에 대한 종이 기록물에 대 한 정량 분석을 하였으며, 그 결과는 Fig. 5(a)에서 보 는 바와 같다. 이 결과는 $900 \mathrm{~nm}$ 부터 $1700 \mathrm{~nm}$ 전체 파장을 선택한 후 baseline correction으로 전처리 하였 다. 정량 분석 방법으로는 부분 최소 제곱 회귀 분석 (PLSR, Regression of partial least square)을 사용하였 으며, PCs(Principle components)를 결정하는 방법으로 cross-validation을 사용하였다. 이때 사용한 소프트웨 어는 Unscrambler (CAMO, USA)를 사용하였다. 그 결과 상관 계수 $(\mathrm{R})$ 는 0.91 으로 선형성이 좋은 것으로 되었으며, SEC (standard error of calibration)은 0.61로 확인 되었다. 그리고 전체 66점 중에서 3 개를 통계처 리에서 제외(Outlier) 하였다. 이 정량 분석에 대한 전 체 파장 대역에 대한 가중치(Loading value)는 Fig. 5(b)의 결과로써 나타내었다. 산성도는 주로 O-H 영역 에서 영향을 주게 되는데 이 가중치에서 가장 큰 가 중치는 $1400 \mathrm{~nm}$ 파장 대역에서 확인 되었지만, 종이 에서는 산성도는 R-OH와 O-H 1차 배음대에서 영향 을 주는 것으로 확인 되었으며, $900 \mathrm{~nm}$ 대역에서도 상관관계에 높은 영향을 주는 것으로 나타났다. 이 파 


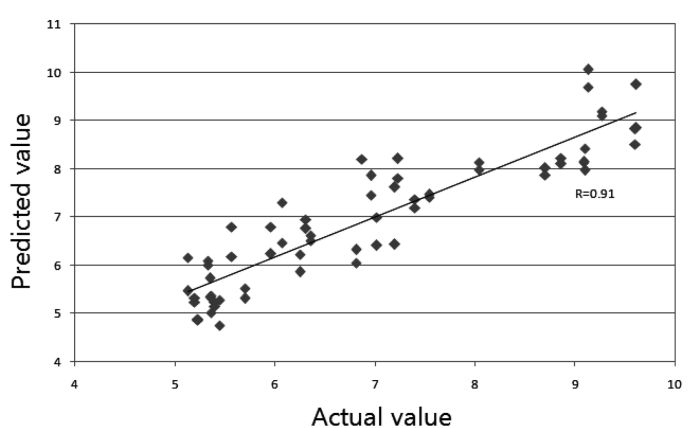

(a)

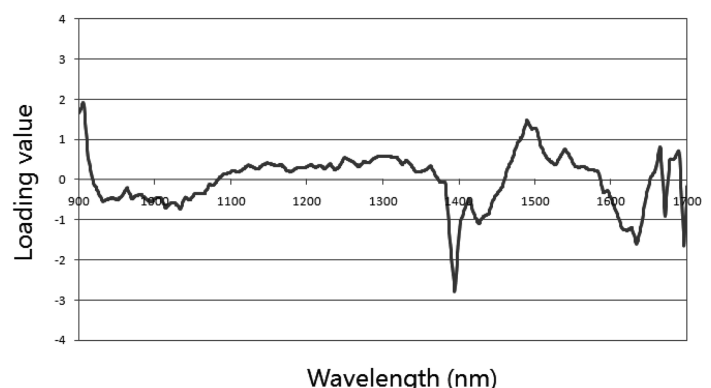

(b)

Fig. 5. Result of $\mathrm{pH}$ calibration curve on record papers.

장 대역에서는 C-H band 3차 배음대와 R-OH band 2 차 배음대가 같이 영향을 주어 낮은 파장에서도 높은 가중치가 보이는 것으로 확인 되었다.

\section{3. 종이의 함수율에 대한 정량 분석}

종이의 함수율과 근적외선 흡수 스펙트럼의 상관관 계를 확인하기 위하여, ISO 11093-3의 oven drying method 방법으로 함수율로 측정하였다. 함수율이 4.33 부터 $9.29 \%$ 의 영역까지 가진 66점의 시료를 가지고 정량 분석을 하였다. 정량 분석 방법은 산성도와 동일 한 조건에서 하였으며, 그 결과는 Fig. 6(a)에서 보는 바와 같다. 이 결과를 보면 상관계수가 0.94 이며, SEC 는 0.40 으로써 산성도에 비해서는 더 높은 상관 계수 및 $\mathrm{SEC}$ 를 확인 할 수 있었다. 또한 산성도일 때는 높 은 선형성을 확보하기 위하여 3 개의 시료를 제외 시 켰지만, 함수율은 시료제외 없이 높은 선형성을 가진 상관관계를 확인 할 수 있었다. 그리고 종이의 함수율 의 정량 분석에 대한 가중치는 Fig. 6(b)에서 나타내 었다. 종이의 함수율에 대한 가중치는 산성도와는 $1400 \mathrm{~nm}$ 에서 $1450 \mathrm{~nm}$ 의 O-H 1차 배음대의 파장 대 역은 유사하지만 $1600 \mathrm{~nm}$ 에서 $1700 \mathrm{~nm}$ 의 파장 대역 인 C-H 1차 배음대와 cellulose 1차 배음대의 가중치 가 산성도에 비해서 더 높은 것으로 확인 되었다. 함 Vol. 25, No. 6, 2012

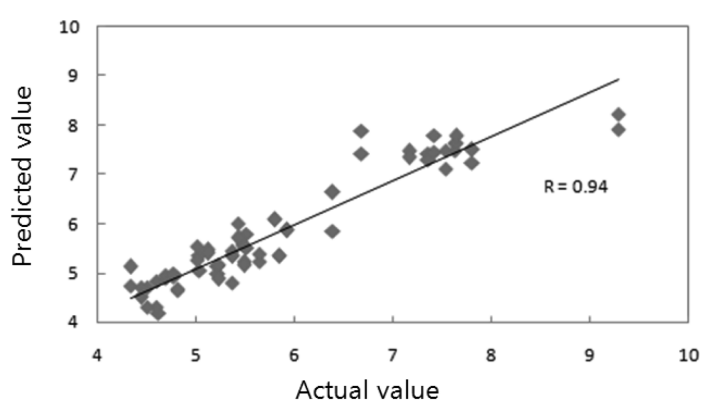

(a)

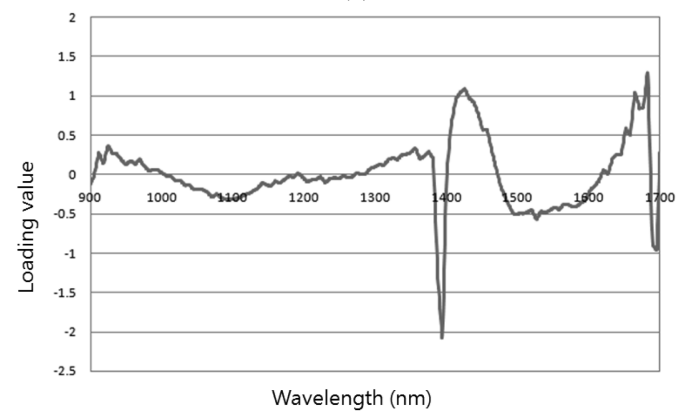

(b)

Fig. 6. Result of moisture calibration curve on record papers.

수율이 직접적으로 O-H band에 영향을 받으면서 O$\mathrm{H}$ band가 낮아지면서 상대적으로 cellulose 농도가 높 아지는 경향도 같이 확인 되었다.

\section{4. 결 론}

본 연구에서는 1970 년부터 2003년까지의 종이 기록 물을 가지고 이동 가능한 소형 근적외선 분광 분석기 와 광파이버를 이용하여 종이 측정한 결과 산성도의 상관 계수는 0.91 이고, 함수율은 0.94 였다. 그리고 각 각의 $\mathrm{SEC}$ 는 0.61 과 0.40 으로써 확인 되었다. 이 결과 를 통하여 종이 기록물을 분석하는 데 있어 비 파괴 적이면서 이동 가능한 소형 근적외선 분광 분석기를 사용하여 정량 분석을 가능 한 것을 확인 할 수 있었 으며, 이를 통하여 이동하면서 측정이 가능한 간이형 분광 분석기의 개발의 가능성을 제시하였다. 그리고 희귀 종이 기록물에 대한 체계적이고, 안정된 조건에 서 관리가 가능할 수 있는 근거를 마련하였다.

\section{감사의 글}

이 발표는 행정 안전부 국가 기록원의 2012년 기록 보존 기술 연구개발 사업의 지원을 받아 수행된 연구임. 


\section{참고문헌}

1. Andrew Richard Albanese, Library Journal, USA (2001).

2. P. Williams and K. Norris, American Association of Cereal Chemists, Inc., Minnesota, USA, 201 (1987).

3. P. Corti, E. Dreassi, G. Ceramelli, S. Lonardi, R. Viviani and S. Gravina, Analysis, 19(7), 198-204 (1991).

4. M. Blanco, J. Coello, A. Eustaquio, H. Iturriaga and S. Maspoch, J. Pharm. Sci., 88(5), 551-556 (1999).

5. G. Lee, C. Han and Yoon, E. S., Chem. Res., 8037-
8048 (2004).

6. H. H. Yoon, Y. M. Shin, H. J. Kim, Anal. Sci. Technol., 23(3), 304-311 (2010).

7. P. R. Armstrong, E. B. Maghirang, F. Xie and F. E. Dowell, Appl. Eng. Agric., 22(3), 453-457 (2006).

8. H. M. Antti, Sjöström, J. Chemom., 10(5-6), 591-603 (1996).

9. H. Y. Cen and Y. He, Food Sci. Technol., 18, 72-83 (2007). 